\title{
INFILTRAÇAXO DO SISTEMA NERVOSO CENTRAL E DAS MENINGES NOS LINFOMAS COM REPRESENTAÇAO LEUCEMICA
}

\author{
MARCO\& R. G. DE FREITAS * \\ HERBERT PRAXEDES ***
}

\author{
PEDRO F'. MOREIRA FILHO ** \\ MYRIAM D. HABN ****
}

As infiltrações leucêmicas constituem agregados de células neoplásicas que podem ser encontradas em qualquer parte do sistema nervoso central ou periférico 1,3,8. Tais infiltrados estão ou não em relação com os vasos sanguíneos. Nestes, há invasão de células blásticas nas diferentes camadas de revestimento formando às vezes verdadeiros nódulos que podem provocar fenômenos compressivos ${ }^{8}$. Tais infiltrados perivasculares são oriundos de vasos sanguineos dilatados e repletos de células blásticas leucostáticas.

As infiltrações seriam resultantes da passagem de elementos neoplásicos do sangue ou decorrentes de transformações leucêmicas de células normais dentro do parênquima nervoso (Cramblett $\left.{ }^{2}\right)$. Segundo Sullivan ${ }^{11}$, a infiltração leucêmica seria uma resposta do mesênquima nervoso a um distúrbio geral do mesênquima no organismo. $O$ tecido nervoso responderia mais tardia e mais lentamente do que o mesênquima de outros órgãos, como a medula óssea, fígado, baço, gânglios, rins e mesmo os ossos.

A conversão num quadro de leucemia pode ocorrer em todos os tipos de linfomas malignos não Hodgkin, tornando mais sombrio o prognóstico dessas neoplasias. Tal conversão se faz, na maioria das vezes, para o tipo linfóide agudo, e ocorre numa frequência que varia de 5 a $35 \%$ (Gendelman e col. 5). Nestes linfomas com representação leucêmica podemos encontrar infiltrados de células blásticas nas meninges e no parênquima nervoso e, até mesmo, hemorragias semelhantes às descritas como complicações das leucemias $1, s, 7,0$.

Dos 87 pacientes com linfomas malignos por nós estudados 4 no período de 5 anos, $18,3 \%$ tiveram manifestações neurológicas. Destes, quatro apresentaram infiltração leucêmica das meninges e parênquima nervoso. Constituem estes casos o motivo do nosso trabalho.

\section{OBSERVACOEES}

Caso 1 - A.V.S. (Registro 115.726, HUAP), 30 anos de idade, sexo feminino, branca, examinada em março de 1976. Início da enfermidade em setembro de 1975, quando

Trabalho da disciplina de Neurologia da Faculdade de Medicina da Universidade Federal Fluminense: * Prof. assistente; ** Assistente de ensino; ** Prof. Adjunto de Hematologia; *** Prof. assistente de Anatomia Patológica. 
surgiram ganglios inguinais indolores, astenia e perda de apetite. Cerca de três meses após, fol feito o díagnóstico de linfossarcoma com representaçăo leucêmica. Nesta época passou a queixar-se de cefaléia generalizada, vômitos e diminuição da acuidade visual. Exame neurológico - Presença de rigidez de nuca. Fundus oculares revelando hemorragias retinianas e estase incipiente das papilas opticas. Restante do exame normal. Exames complementares - Radiografias de cranio normais. Liquido cefalorraqueano claro, transparente, com $34 \mathrm{~cm} \mathrm{H}_{2} \mathrm{O}$ de pressåo. Citologia: 260/mms (100\% bléstícas); proteínas 46mg\%; glicose 38mg\%; cloretos $121 \mathrm{mEq} / 1$. Evoluço - Logo após o início da terapéutica sintemica e intratecal (metotrexate), tornou-se a paciente sonolenta entrando progressivamente em coma e falecendo um més após a internação. Exame anatomo-patologico do sistema nervoso - Presença de pontilhados esbranquiçados na trajetória dos vasos subacnóideos. Lesáo necro-hemorrágica localizada na substancia cinzenta no corte passando pela ponta do lobo temporal, medindo $1,2 \mathrm{~cm}$ no seu maior diametro. O corte passando pelo quiasma óptico mostra pequenas lesões necro-hemorrágicas localizadas nas circunvoluçóes e núcleos da base (Fig. 1). Microscopia - Observa-se meninges espessadas à custa de infiltrajos de células neoplásicas de origem mesenquimal exibindo núcleos evidentes e citoplasmas escassos. Tals células encontram-se dentro das lesర̃es vasculares infiltrando diretamente o córtice cerebral (Fig. 2). A substancia branca evidencia extensas áreas comprometidas pela neoplasia maligna, notando-se que as células blásticas dispz̃em-se sob a forma de nódulos que estăo circundađos por halos hemorrágicos (Fig. 3). As células nervosas revelam graus variados de cromatólise e a st:bstancia branca evidencia aspecto esponjoso. Observa-se também infiltração de células leucêmicas ao nível da camada molecular e granulosa do cerebelo, formando nódulos que, também, se acham envoltos por halos hemorrágicos (Fig. 4).

Caso 2 - A.C.O. (Registro 66.636, HUAP), 14 anos de idade, sexo masculino, branco, examinado em agosto de 1972. Por apresentar adenomegalia generalizada foi submetido a bíbsia de ganglio que revelou tratar-se de retículossarcoma. Sete dias após apresentou agitaçáo psicomotora e crise convulsiva generalizada. Exame neurolójico - Paciente em coma profundo com hipotonia e arreflexia generalizada năo reagindo aos estímulos álgicos. Pupilas em midríase paralítica. Abolição dos reflexos cilio-espinhal, óculo-céfalogiro e córneo-palpebral bilateralmente. Exames complementares - Leucocitose de $246.000 / \mathrm{mm} 3$ com 98\% de células blásticas. Evolugáo - Logo após a internaçáo, foi levado o paciente ao Centro de Tratamento Intensivo, falecendo, em seguida.

Exame anatomopatologico do sistema nervoso central - Amolecimento hemorrágico no hemisfério cerebral direito e amolecimento no núcleo lenticular esquerdo. Microscopia - As leptomeninges revestindo o córtice cerebral e cerebelar, apresentando-se espessadas e mostrando vasos dilatados preenchidos por células neoplásicas de linhagem mesenquimal exibindo núcleos volumosos com nucléolo evidente. Tais células são observadas dentro dus vasos da substancia cinzenta e branca cerebrais. Estes elementos formam nódulos de tamanhos variáveis, circundados por extensas áreas de hemorragia e material eosinofilico amorfo (Fig. 5).

Caso 3 - D.C.S. (Registro 158.280, HUAP), 40 anos de idade, sexo masculino, branco, examinado em abril de 1978. Fm dezembro de 1977, fol feito o diagnóstico de linfossarcoma mediante biópsia ganglionar. Em abril de 1978, apos ter apresentado representação lelicêmica da reticulose, o paciente passou a queixar-se de forte cefaléla, dimi- 
428 ARQ. NEURO-PSIQUiATRIA (SAO PAULO) VOL. 39, No 4, DEZEMBRO, 1981

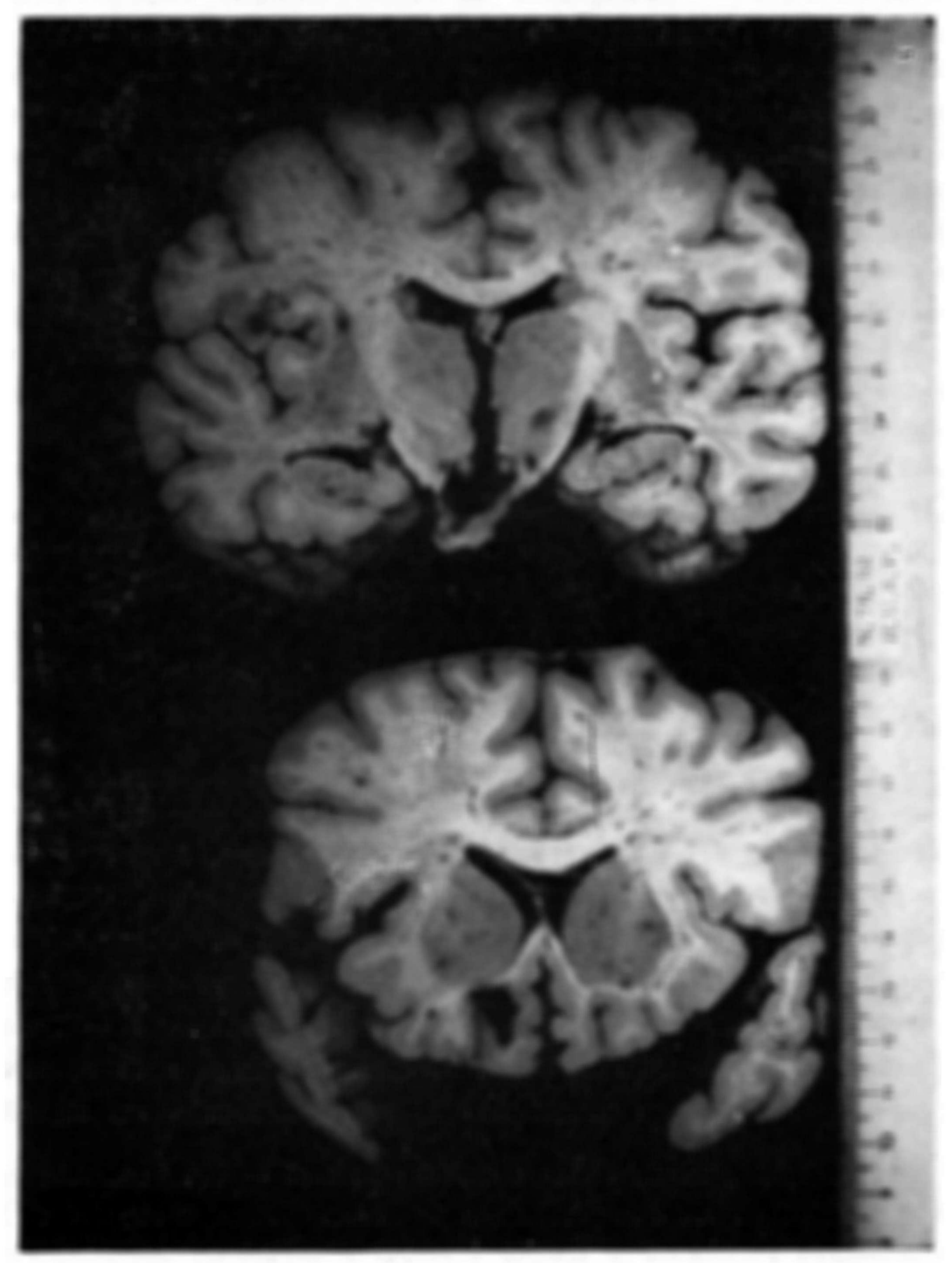

Fig. 1 - (A.V.8.). Corte superior: pequenas lesobs necro-homorragicas localieadas nas circunvolucóses a nucleos de base. Corte inferior: lesdo necro-hemorrdoica looalieada na substancia cineenta. 


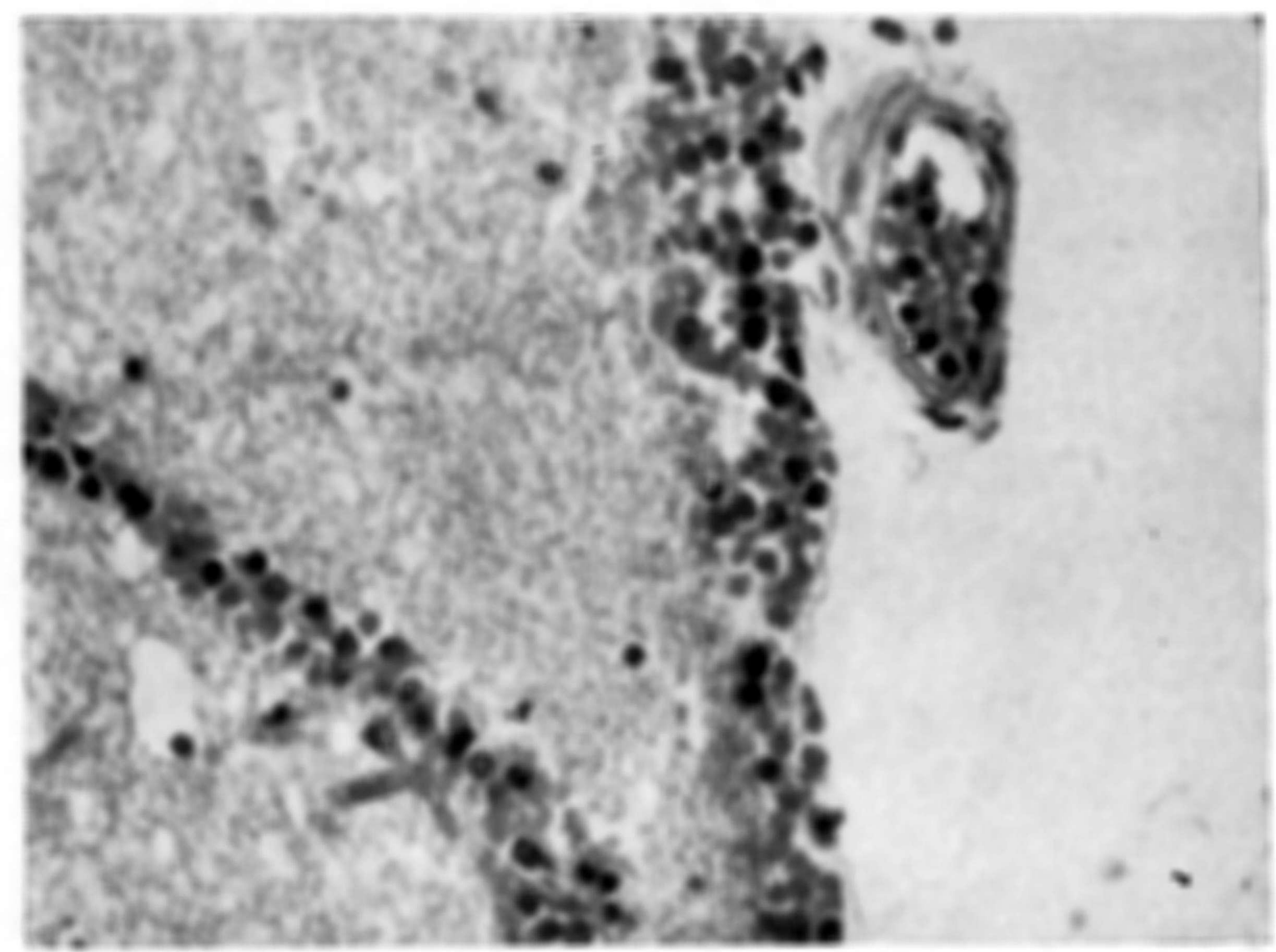

Fig. 2 - (C'aso 1, A.V.8.). Leptomeningite por infiltraçáo de células neopldisicas evidenciando-se ainda hemacias livres (H.E. 20x).

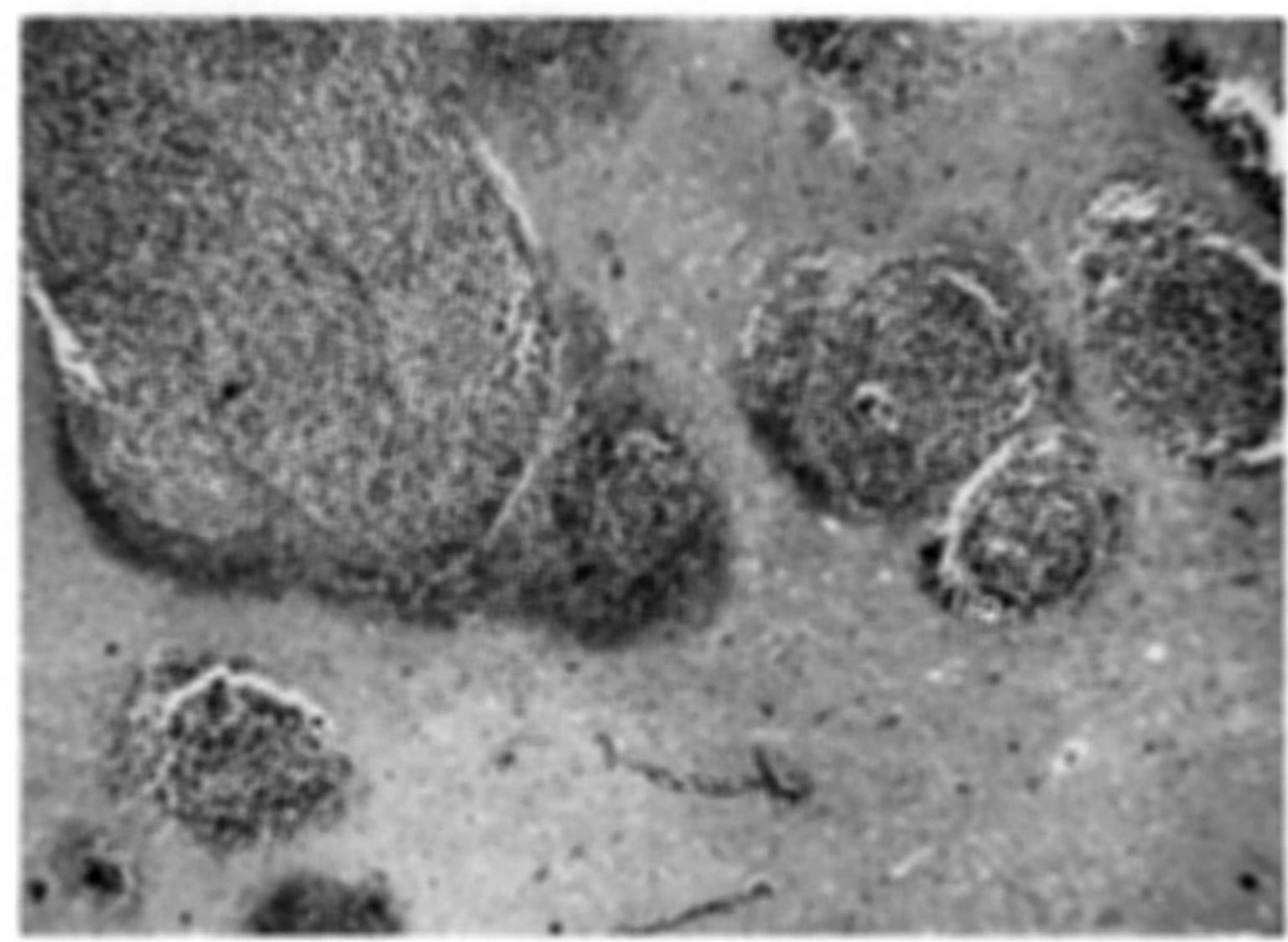

Fig. 3 - (Caso 1, A.V.S.). Infiltragio noopldisica na substancia branca sob a forma de nodulos, apresentando-se alouns circundados por halos hemorrdgicos (H.E. sx). 


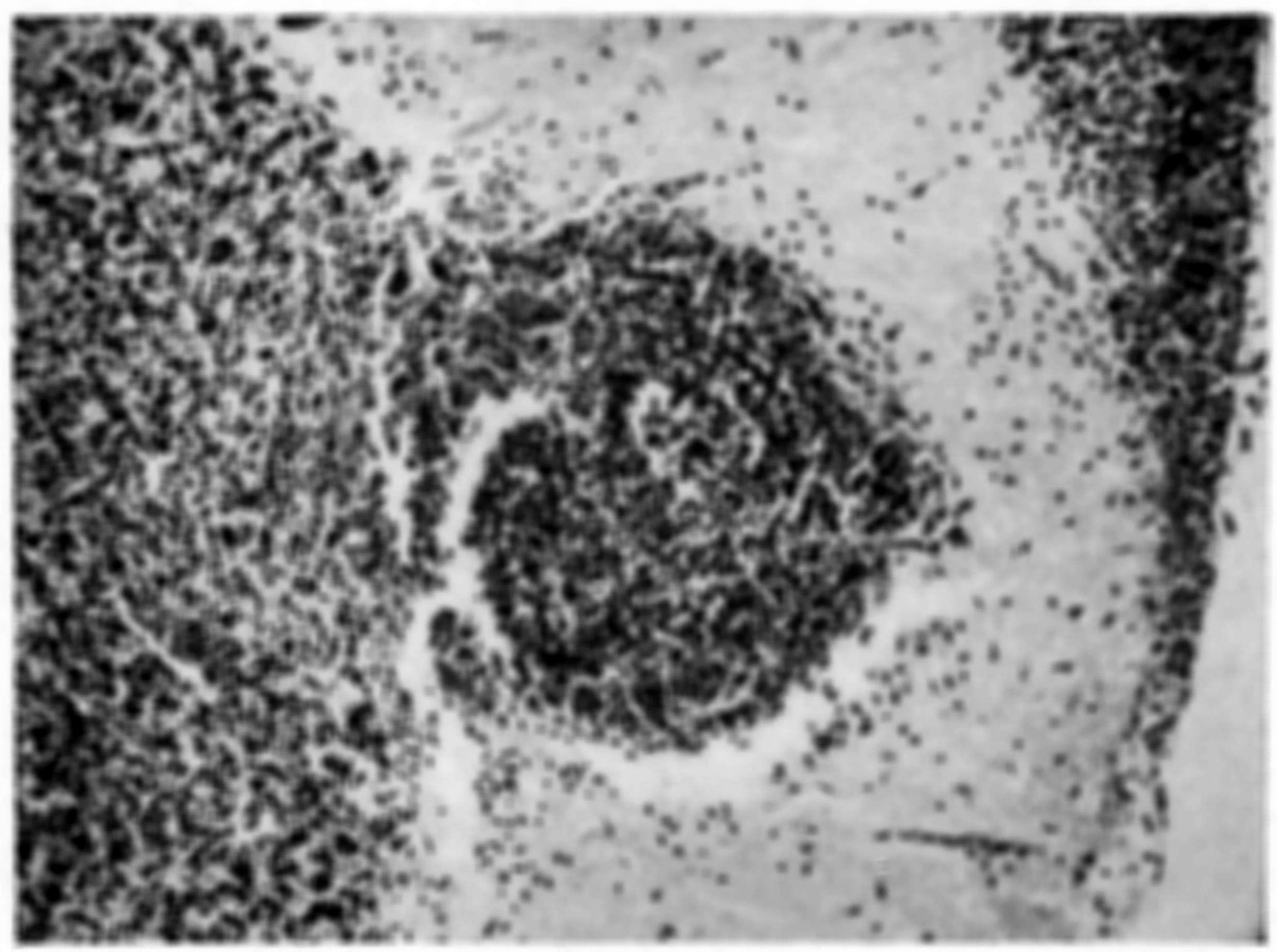

Fig. 4 - (Caso 1, A.V.8.). Presenga de infiltragdo neopldsica a nivel de cerebelo, localizada no espaco subrancosideo, atingindo a camada molecular na qual evidencia-se nodulo tumoral envolto por hemorragia (H.E. 6x).

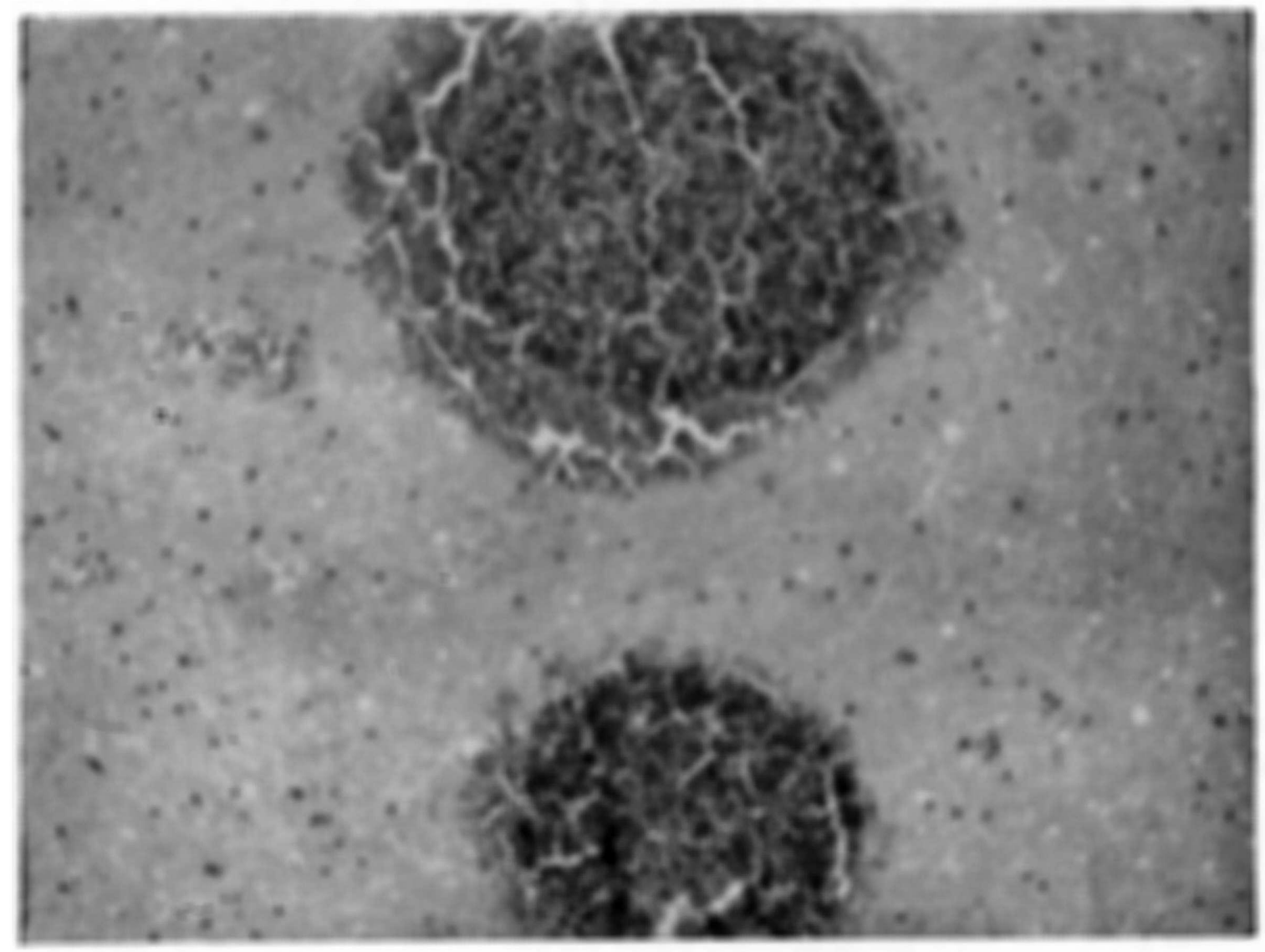

E4g. 5 - (Caso 8, A.C.O.). Infntragdo de cedilas neopldstcas na substancia branca fortando nodulos que se acham envolvidos por hemorragia (H.E. $6 x$ ). 
nuiçăo da acuidade visual e vômitos. Exame neuroĺgico - Presença de sinal de Brudzinaki, arraflexia profunda generalizada e edema incipiente de paplla óptica a esquerda. Restante do exame normal. Exames complementares - Radiografias de cranio normais. Liquido cefalorraqueano opalescente com $30 \mathrm{~cm} \mathrm{H}_{2} \mathrm{O}$, de pressăo. Citologia: 610 células/mm3 (100\% blésticas), proteínas $75 \mathrm{mg} \%$, glicose 15mg\%, cloretos $110 \mathrm{mEq} / 1$. Evoluço - Iniciado o uso do metotrexate por via intratecal houve regressăo do quadro neurológico e liquórico, em sete dias. Alguns dias após o paciente apresentou-se com extremidajes frias entrando em choque septicemico, falecendo horas após. Exame anatomopatologico do sistema nervoso central - sem alteraçóes.

Caso 4 - M.M.R. (Registro 104.127, HUAP), 16 anos de idade, sexo masculino, branco, examinado em abril de 1975. No final de 1974 queixou-se o paciente de astenia e perda de apetite. Na época foi feito o diagnóstico de linfossarcoma com representacão leucêmica. Medicado, apresentou evidente melhora. Quatro meses após, passou a apresentar cefaléia, vômitos e distúrbios visuais. Exame neurológico - Presença de rigidez da nuca e sinal de Kernig. Discreto edema das papilas ópticas. Exames complementares - Radiografias de cranio normais. Liquido cefalorraqueano turvo com $40 \mathrm{~cm} \mathrm{H}_{2} \mathrm{O}$ de pressåo. Citologia: 4970 células/mm3 (100\% blásticas), proteinas 139mg\%; glicose 75mg\%; cloretos 125mEq/1. Evolucăo - Foram introduzidos na medicaçăo o metotrexate por via intratecal e a radioterapia craniana (2200 rads). Em po:co tempo, houve normalização do exame neurológico e do líquido cefalorraqueano. Dois meses após apresentou septicemia, falecendo em seguida.

Exame anatomopatoĺógico do sistema nervoso - Cérebro e envoltórios meningeos sem alteraçőes.

\section{COMENTARIOS}

A representação leucêmica, exclusiva dos linfomas não-Hodgkin, é mais frequentemente encontrada nos linfossarcomas. Nesta eventualidade, podemos encontrar infiltrados de células leucêmicas nas meninges e no parênquima nervoso e, até mesmo hemorragias semelhantes às descritas como complicações das leucemias $1,3,7,0$.

Gendelman e col. 5 estudaram dois grupos de pacientes com linfomas malígnos. No primeiro (47 pacientes) com representação leucêmica, as manifestações neurológicas foram de $40,4 \%$. No segundo (48 pacientes), em que não houve conversão em leucemia, 23\% apresentaram alterações nervosas. Nos pacientes do primeiro grupo o exame do líquido cefalorraqueano evidenciou intensa pleocitose com presença de células blásticas, e também queda da concentração da glicose. Julgaram os referidos autores que a raquicentese e o exame do líquido cefalorraqueano deveriam ser feitos de rotina, em pacientes com linfomas malígnos que sofressem conversão leucêmica. A hipoglicorraquia, segundo Gilbert e Rice ${ }^{6}$, seria devida à atividade glicolítica das células blásticas.

Os nossos quatro pacientes apresentaram linfomas malignos com representação leucêmica e infiltração de células blásticas nas meninges e sistema nervoso central ( 3 com linfossarcoma e 1 com reticulossarcoma). Nos casos 1 e 2, o exame anatomopaltológico do sistema nervoso central revelou a presença de 
células neoplásicas nas meninges e no encéfalo. Em ambos o estudo microscópico mostrou a formação de nódulos leucêmicos circundados por halos hemorrágicos, localizados no parênquima cerebral e cerebelar. Nos casos 2 e 3 o acometimento neurológico limitou-se clinicamente à presença de sindrome meníngea por infiltração de células leucêmicas. A normalidade do sistema nervoso e envoltórios meníngeos, à necropsia, justificou-se pela regressão do quadro clínico e liquórico, pouco tempo depois de iniciada a terapêtutica específica: metotrexate por via intratecal no caso 3 e o mesmo fármaco associado à radioterapia, no caso 4 . E importante ainda, a observação da intensa hipoglicorraquia encontrada no caso 3.

RESUMO

Os autores fazem referência a 4 pacientes com representação leucêmica no decurso de linfomas malignos que apresentaram infiltração de células neoplásicas no sistema nervoso central e meninges. E feito o estudo anatomopatológico, encontrando-se em 2 deles a formação de nódulos leucêmicos no parênquima nervoso. Nos outros dois, houve regressão total de sintomatologia neurológica com o uso do metotrexate por via intratecal.

\section{SUMMARY}

Meningeal and central nervous system infiltration in lymphomas with leukemic conversion: report of four cases.

The cases of four patients with lymphoma with leucemic conversion, who exhibitted neoplasic infiltration of the central nervous system and of the meninges are reported. The anatomo-pathologic study showed the presence of small nodules of leucemic cells, in two patients. The other two patients had clinical improvement after the use of metotrexate by spinal route so that the anatomopathologic study of their CNS and meninges showed no abnomality.

\section{REFERENCIAS}

1. CAMBIFR, J.; LECHEVALIER, B. \& LHUILLIER, M. - Les complications neurologiques des hémopathies malignes. Rev. Prat. (Paris) 19:763, 1969.

2. CRAMBLETT, H.G. - Recognition and treatment of intracranial manifestations of leukaemia. Dis. Child. 97:805, 1959.

3. D'ERAMO, N. \& LEVI, M. - Neurological Symptoms in Blood Diseases. University Park Press, Baltimore, 1972.

4. FREITAs, M.R.G. - Contribuiçăo para o estudo das manifestaçóes neurológicas das leucemias e dos linfomas. Tese de mestrado, UFRJ, 1979.

5. GENDELMAN, B.; RIZZO, F. \& MONES, R. J. - Central nervous system complications of leukaemic conversion of lymphomas. Cancer 24:676, 1969. 
6. GILBERT, E. F. \& RICE, E. C. - Neurologic manifestations of leukaemia: report of three cases in children simulating acute bacterial meningites. Pediatrics 19: $801,1957$.

7. HUSTU, H. O. \& AUR, R. J. A. - Extramedullary leukaemia. Clinics Haemat 7:313, 1978.

8. LEIDLeR, F. \& RUSSEL, W. O. - The brain in leukaemia. Arch. Pathol., 40:14, 1945.

9. PHAIR, J. P.; ANDERSON, R. E. \& NAMIKI, H. - The central nervous system in leukaemia. Ann. Intern. Med. 61:863, 1964.

10. SHAW, R. K.; MOORE, E. W.; FREIREICH, E. \& THOMAS, L. B. - Meningeal leukaemia. Neurology (Minneapolis) 10:823, 1960.

11. SULLIVAN, M. P. - Leukaemia infiltration of meninges and spinal nerve roots. Pediatrics 32:63, 1963.

Disciplina de Neurologia da Fraculdade de Medicina - Universidade F'ederal Fluminense - Hospital Universitdrio Antondo Pedro - Rua Marques do Parand s/no 24.000 Niteroi, $R J$ - Brasil. 